\title{
Tomographic diagnosis and relevant aspects of otosclerosis*
}

Diagnóstico tomográfico e aspectos relevantes da otosclerose

\author{
Juliana Oggioni Gaiotti ${ }^{1}$, Natália Delage Gomes ${ }^{1}$, Ana Maria Doffémond Costa ${ }^{1}$, Caroline Laurita \\ Batista Couto Villela ${ }^{1}$, Wanderval Moreira ${ }^{2}$, Renata Lopes Furletti Caldeira Diniz ${ }^{2}$
}

\begin{abstract}
A literature review and pictorial essay were developed to discuss the importance of knowing the main findings and locations of otosclerosis at multidetector computed tomography (MDCT). The authors performed a retrospective review of cases of otosclerosis diagnosed in their institution by means of high resolution multidetector computed tomography. Otosclerosis corresponds to otic capsule dysplasia characterized by metabolic derangement of its endochondral layer. Such condition constitutes a relevant cause of sensorineural hearing loss, affecting about $7 \%$ to $10 \%$ of the general population. The diagnosis is usually clinical, but imaging methods play a significant role in the anatomical detailing, differential diagnosis, surgical planning and evaluation of postoperative complications. Among such methods, the relevance of MDCT is highlighted. Radiologists should be familiar with the MDCT findings of otosclerosis, as well as with the temporal bone anatomy to assist in the appropriate clinical management of this disease.
\end{abstract}

Keywords: Otosclerosis; Otospongiosis; Sensorineural hearing loss; Multidetector computed tomography.

Resumo Revisão da literatura e ensaio iconográfico foram realizados com o objetivo de discutir a importância do conhecimento das principais características e localizações da otosclerose à tomografia computadorizada multidetectores (TCMD). Foi feita avaliação retrospectiva de casos de otosclerose diagnosticados em nosso serviço, em equipamento multidetectores com técnica de alta resolução. A otosclerose é uma displasia da cápsula ótica, caracterizada pelo desarranjo metabólico de sua camada endocondral. É uma importante causa de perda auditiva neurossensorial, com incidência de cerca de $7 \%$ a $10 \%$ da população geral. 0 diagnóstico usualmente é clínico, porém os métodos de imagens são de grande valia para o detalhamento anatômico, diagnóstico diferencial, planejamento cirúrgico e avaliação de complicações pósoperatórias. Dentre esses métodos, deve-se ressaltar o importante papel da TCMD. Os radiologistas devem estar familiarizados com as características da otosclerose, assim como com a anatomia do osso temporal à TCMD, para auxiliar no manejo clínico adequado desta doença.

Unitermos: Otosclerose; Ostospongiose; Hipoacusia neurossensorial; Tomografia computadorizada multidetectores.

Gaiotti JO, Diniz RLFC, Gomes ND, Costa AMD, Villela CLBC, Moreira W. Tomographic diagnosis and relevant aspects of otosclerosis. Radiol Bras. 2013 Set/Out;46(5):307-312.

\section{INTRODUCTION}

Otosclerosis is an important cause of sensorineural hearing loss, affecting approximately $7 \%$ to $10 \%$ of the general population. Otosclerotic lesions may originate in most regions of the osseous labyrinth, presenting clinical and radiological characteristics in accordance with the affected site. In such a context, multidetector computed tomography (MDCT) has been

* Study developed at Hospital Mater Dei, Belo Horizonte, MG, Brazil.

1. MDs, Trainees in Radiology and Imaging Diagnosis, Hospital Mater Dei - Mater Imagem, Belo Horizonte, MG, Brazil.

2. MDs, Radiologists, Preceptors at the Unit of Radiology and Imaging Diagnosis, Hospital Mater Dei - Mater Imagem, Belo Horizonte, MG, Brazil.

Mailing Address: Dra. Juliana Oggioni Gaiotti. Rua Rio Grande do Sul, 1158, ap. 1001, Santo Agostinho. Belo Horizonte, MG, Brazil, 30170-111. E-mail: jugaiotti@gmail.com.

Received July 5, 2012. Accepted after revision March 18, 2013 increasingly utilized, as it allows for the characterization, localization and diagnostic confirmation of the lesion, besides being useful in the surgical planning and differential diagnosis. Thus, the radiologist should be familiar with the peculiarities of such a disease, as well as with the anatomic detailing of the temporal bone on this method. A literature review and a pictorial essay were developed, highlighting the main sites affected by such a disease as well as its main characteristics.

The authors carried out a retrospective review of cases of otosclerosis diagnosed in their institution by scans performed in a 64-chanel Toshiba MDCT apparatus, with volumetric acquisitions in the axial plane, with inframillimetric slices $(0.2 \mathrm{~mm})$ and high resolution technique, to evaluate bone structures and multiplanar reconstructions in the axial, coronal and oblique planes without utilizing iodinated contrast agent, allowing a better evaluation of the stapes footplate and of the oval window ${ }^{(1)}$.

\section{DISCUSSION}

Otosclerosis (otospongiosis) is a chronic inflammatory disease limited to the temporal bone, which causes metabolic derangement of the endochondral layer of the otic capsule ${ }^{(2,3)}$. Such condition is characterized by an initial osteolysis (spongiosis) followed by a reconstruction with dense dysplastic bone (sclerosis). Thus, the words otospongiosis and otosclerosis are two different names for two stages of a single disease, and otosclerosis is the last stage of such disease ${ }^{(4)}$.

This disease has an incidence of $7 \%$ to $10 \%$ in the general population, usually with onset at the 3rd or 4th decades of life, and 
rarely before the 10 th year of age ${ }^{(\mathbf{5})}$. It predominates in the white population and among female individuals at a $2: 1$ ratio, and it may worsen during pregnancy.

Clinically, otospongiosis is characterized by progressive, sensorineural or mixed conductive dysacusis, and by the presence of tinnitus ${ }^{(\mathbf{5})}$. Conductive hearing loss is generally secondary to the involvement of the stapes footplate ${ }^{(\mathbf{5 , 6})}$, while in sensorineural or mixed hearing loss the physiopathogenic mechanisms are still to be completely understood. It is believed that it is caused by direct injury to the cochlea and spiral ligament $^{(\mathbf{6})}$.

The clinical condition and the otoscopic findings are very characteristic in most cases. The imaging studies play an important role in the non-characteristic cases, in anatomic detailing, in the differential diagnosis, surgical planning and postoperative complications evaluation ${ }^{(\mathbf{5 , 6})}$. Among imaging methods, MDCT has been widely utilized, as it allows for the evaluation of the windows, stapes footplate thickness, bone density of the cochlear capsule, endosteal involvement, preoperative anatomy, diagnosis confirmation, lesions location and extent.

Identifying otosclerotic foci at MDCT, however, is more difficult than identifying spongiotic lesions ${ }^{(\mathbf{1 , 2 , 6 , 7})}$, because of the similarity between the density of sclerotic lesions and that of a normal otic capsule. Such areas of sclerosis are only visualized in those cases where the disease causes stapes footplate thickening, obliteration of vestibular and cochlear windows, distortion of the labyrinthine contour and intralabyrinthine ossification ${ }^{(7)}$.

It is important to highlight, however, that in up to $10 \%$ of the cases the otosclerosis focus may not be identified at computed tomography (infra-radiological otospongiosis) $^{(\mathbf{8})}$.

Magnetic resonance imaging, on its turn, may be useful in the detection of otosclerotic foci, but, on because of the small number of cases described in the literature, diagnostic difficulties may be encountered as such imaging method is the first to be utilized in the investigation of patients with sensorineural hearing loss. Its main role has been the investigation of active focus, intracanalicular extension from the focus and, particularly, detection of postoperative complications ${ }^{(\mathbf{9})}$.

Several imaging classification systems have been proposed by different authors for grading and detailing otosclerosis at computed tomography, but up to the present moment, there is not a universally accepted classification system $^{(\mathbf{6})}$.

Currently, the Veillon ${ }^{(\mathbf{1 0})}$ classification (Table 1) is still being utilized, but such a classification does not present any clinical correlations.

The utilization of the Symons and Fanning classification (an anatomical classification of the disease) ${ }^{(\mathbf{6})}$ has recently been suggested. It is believed that such grading still maintains clinical correlation, however
Table 1 Veillon classification.

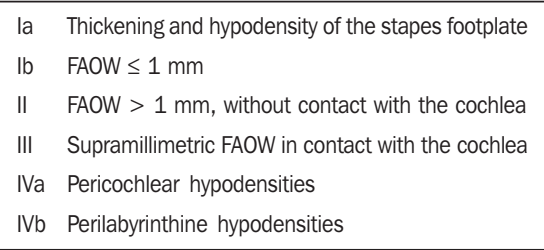

* FAOW: focus anterior to the oval window.

further investigation correlating such grading with audiometry studies are necessary to confirm such assumption ${ }^{(6)}$.

Otosclerotic lesions may originate in most regions of the osseous labyrinth, presenting peculiar radiological and clinical characteristics according to the affected site, and thus it can be divided into fenestral otosclerosis and retrofenestral otosclerosis.

In $80 \%$ to $90 \%$ of cases, such pathological process is of the fenestral type, and it develops in the so called "predilection area", close to the fissula ante fenestram, where hypodensity is observed anteriorly to the oval window (Figure1), in the angle between the staple footplate, the cochleariform process and the promontory ${ }^{(\mathbf{5 , 1 1})}$. For that reason, such region should be considered as being the most important one in the radiological diagnosis of otosclerosis, and should always be carefully screened at imaging studies.

The cases where obliteration of such window occurs (obliterative otosclerosis) are particularly challenging for the surgeons. Obliterative otosclerosis (Figure 2)

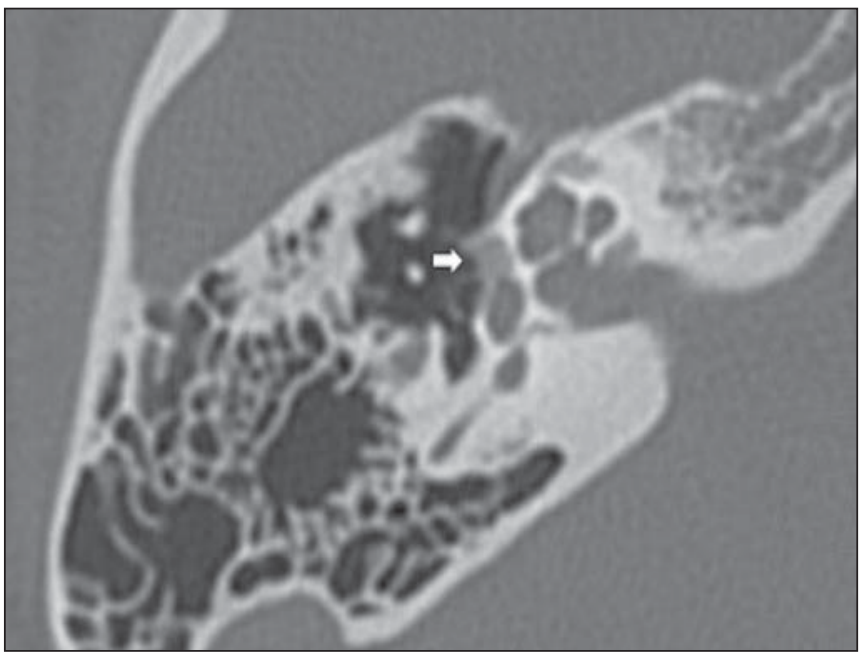

Figure 1. Axial CT section. Hypodensity anterior to the oval window (arrow).

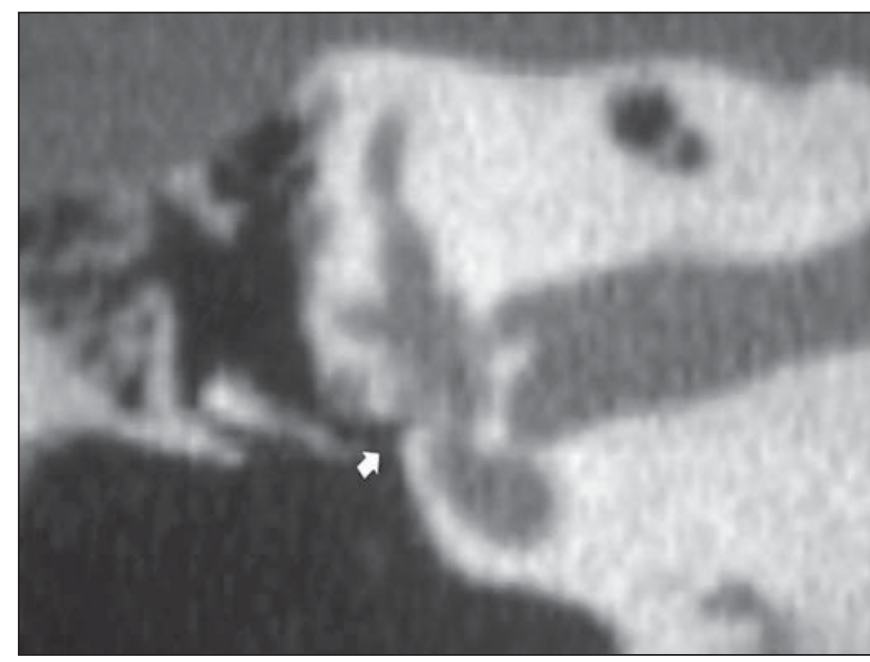

Figure 2. CT, coronal reconstruction. Obliteration of the oval window (obliterative otosclerosis). 
has an incidence of $1 \%$ to $33 \%$ and can be defined as the stapes footplate thickening, usually above $0.6 \mathrm{~mm}$, where the oval window is filled by the otosclerotic lesion in variable proportions, and the annular ligament is completely compromised, thus impairing the delineation of the vestibular fenestra margins ${ }^{(5,12)}$.

The presence of the focus in the stapes footplate (Figure 3 ) at MDCT is a very useful information, particularly in patients selected for stapedotomy and/or stapedectomy, since such finding may represent a significant cause of unsuccessful stapes surgeries $^{(7,12)}$.

Another commonly affected site (often simultaneously to oval window involvement, in more severe cases of disease $\left.{ }^{(\mathbf{1 1})}\right)$ is the round window edge (Figure 4), with incidence ranging from $20 \%$ to $50 \%{ }^{(5,7)}$. Usually, the involvement of the round window has a worse prognosis after surgery ${ }^{(\mathbf{5 , 8 , 1 2})}$, as its presence can affect the sound wave compensation.

Other less common fenestral otosclerotic foci are the cochlea promontory, in the region between the two labyrinthine windows and the focus affecting the canal of the facial nerve in the tympanic segment ${ }^{(7)}$.

The retrofenestral foci constitute approximately $15 \%$ of the otosclerosis cases. Among those, cochlear involvement should be highlighted. Such an involvement is usually symmetrical and bilateral ${ }^{(5)}$.

The visualization of the focus in the cochlea and its location in specific parts of the cochlea is important, and clinically correlated with loss of determined frequencies.

In cases of cochlear involvement (Figure 5) it is possible to identify at MDCT the typical appearance of double hypodensity of the cochlea (double ring sign) produced by the demineralization of the endochondral layer involving the hypodense cochlear membrane, and which may be limited to a segment of the cochlea or even surround its entire contour $^{(\mathbf{5 , 6 , 1 3})}$. Such pericochlear foci may also be divided into two types, namely, without endosteal involvement and with endosteal involvement (Figure 6), the latter being considered a more severe form of otosclerosis $^{(2)}$. In general, endosteal involvement occurs when the focus is in close contact with the endosteal layer of the co-

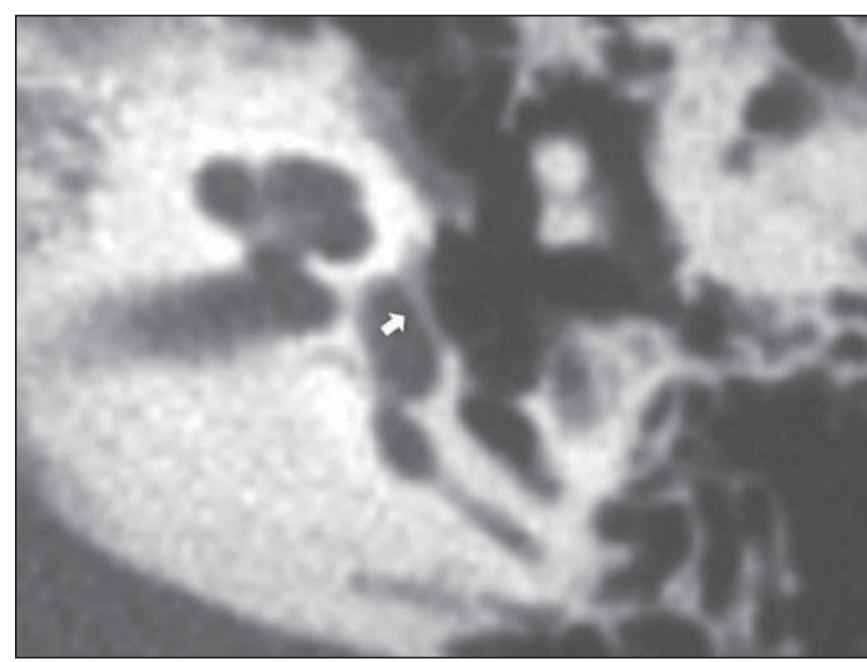

Figure 3. Axial CT section. Stapes footplate thickening (arrow).

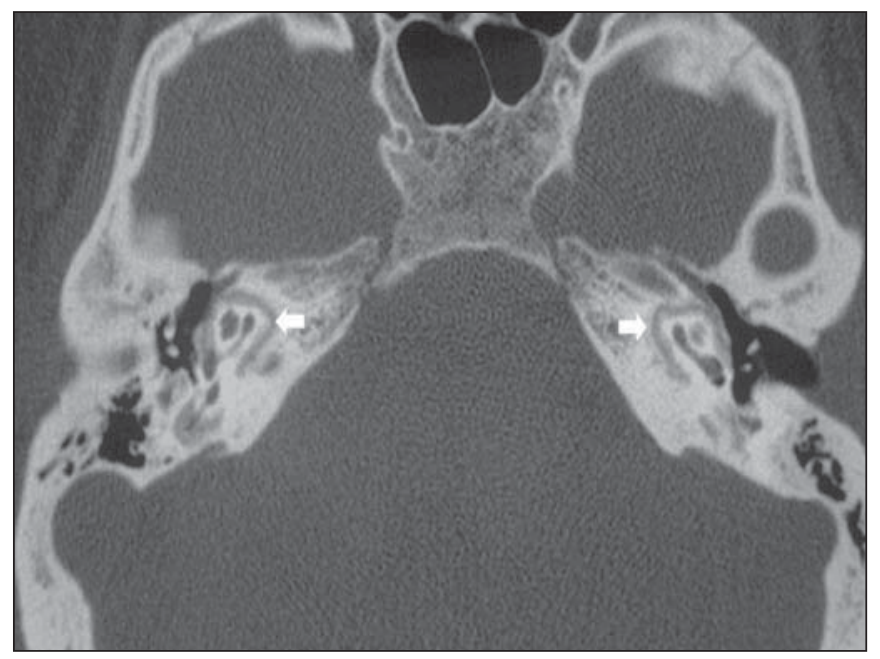

Figure 5. Axial CT section. Pericochlear focus (arrows), bilaterally.

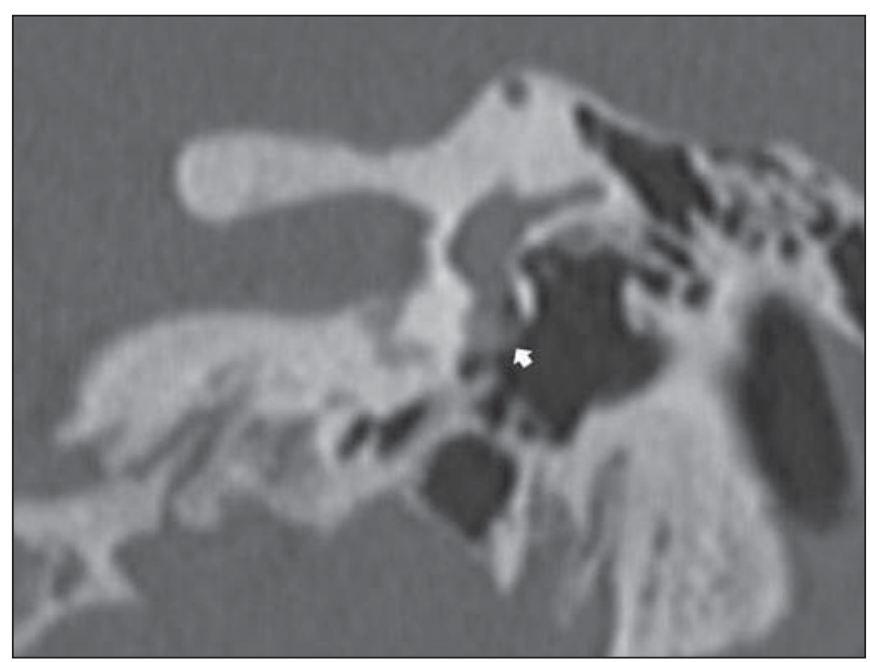

Figure 4. CT, coronal reconstruction. Focus in the round window (arrow).

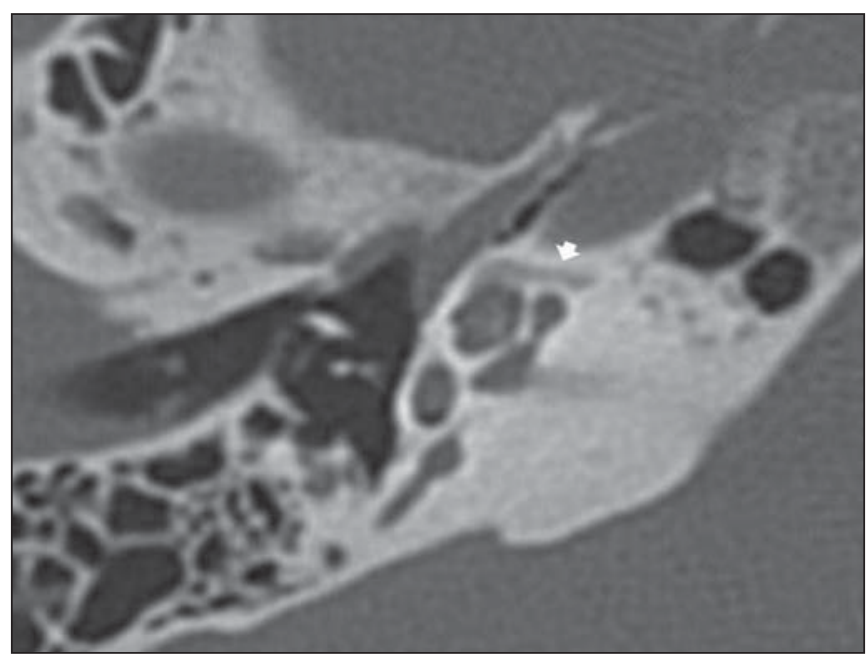

Figure 6. Axial CT section. Pericochlear focus with endosteal involvement (arrow). 
chlea, with possible release of enzymes into the labyrinthine fluid and consequential inflammation and degeneration of intracochlear structures.

Foci adjacent to the semicircular canals; foci located anteriorly to the internal acoustic meatus (Figure 7), intralabyrinthine foci (Figure 8), ossicular foci (Figure 9), and foci in the posterior labyrinth (Figure 10) can also be identified in patients with retrofenestral otosclerosis ${ }^{(\mathbf{1})}$.

The radiologist should initiate the study by investigating the anterior region to the oval window, which is the most affected site (fissula ante fenestram) with special attention on the stapes footplate and to the possibility of obliterative otosclerosis. Subsequently, the round window should be as- sessed, as it is the second site in frequency of involvement. After that, the investigation of retrofenestral foci is suggested, emphasizing the relevance of assessing the endosteal involvement, and finally, the study of the already mentioned, less common foci.

Axial sections are fundamental in the radiological approach of patients with fenestral otosclerosis, for their higher accuracy, particularly in those cases of focus located anteriorly to the oval window, where the axial oblique plane plays an important role. The coronal view is useful for detecting thickening and obliteration in the round windows, in the foci in the promontory and related to the tympanic segment of the facial nerve. As regards the assessment of retrofenestral otosclerosis, there are no statistically significant differences between the axial and coronal views ${ }^{(2,7)}$.

In the preoperative evaluation ${ }^{(\mathbf{1 2})}$, the following items are relevant and should be observed: narrowing of the oval window (either congenital or secondary to dehiscence of the facial nerve, obliterative otosclerosis of the oval window, obliteration of the round window (Figure 11), endosteal involvement, labyrinthine malformations, ossicular chain fixation, superior semicircular canal dehiscence, dilated vestibular aqueduct (Figure 12) and distance between the lenticular process of the incus and the stapes footplate (Figure 13), so that the surgeon can estimate the size of the prosthesis to be utilized.

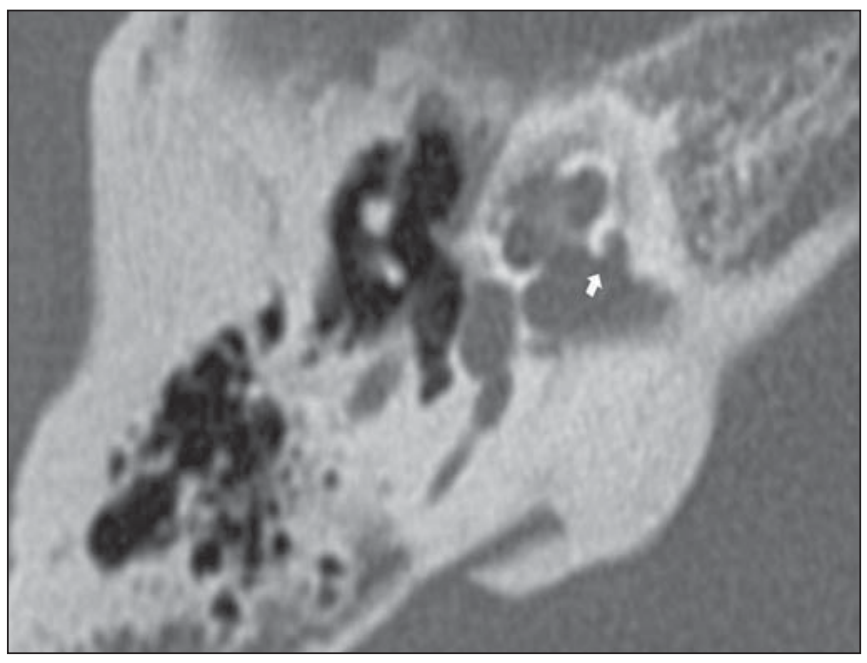

Figure 7. Axial CT section. Focus anterior to the internal auditory canal (arrow).

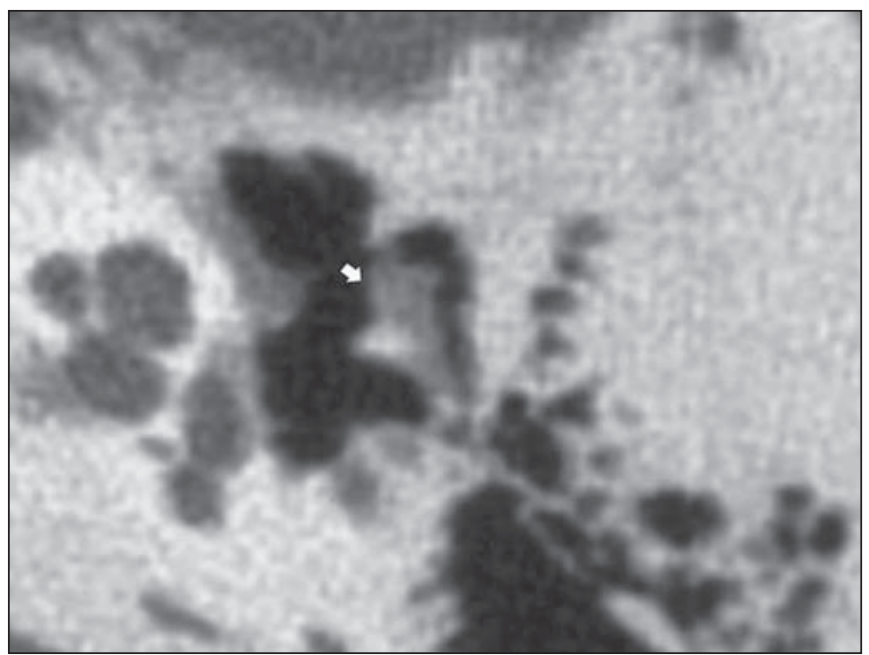

Figure 9. Axial CT section. Ossicular focus (arrow).

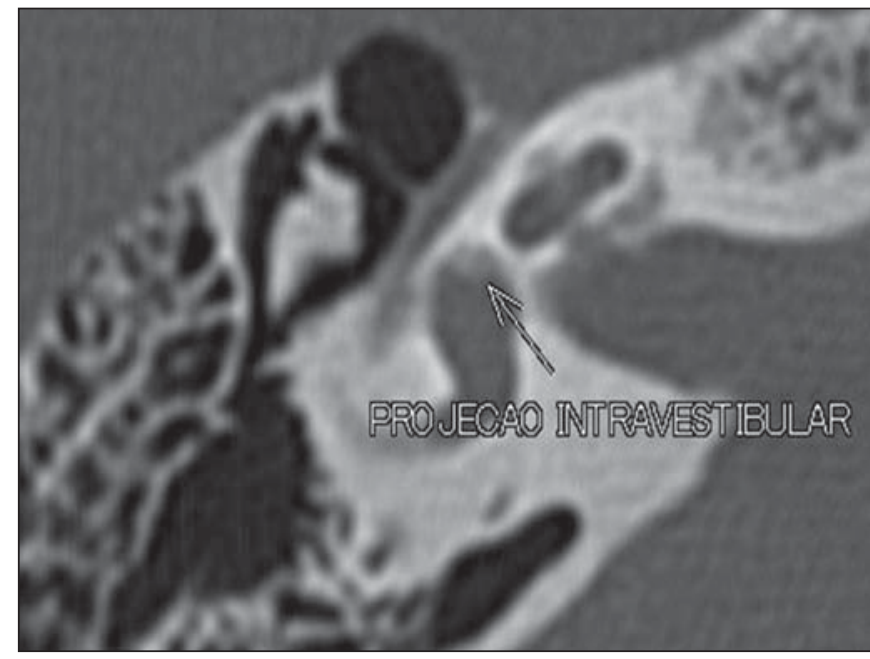

Figure 8. Axial CT section. Intralabyrinthine focus (arrow).

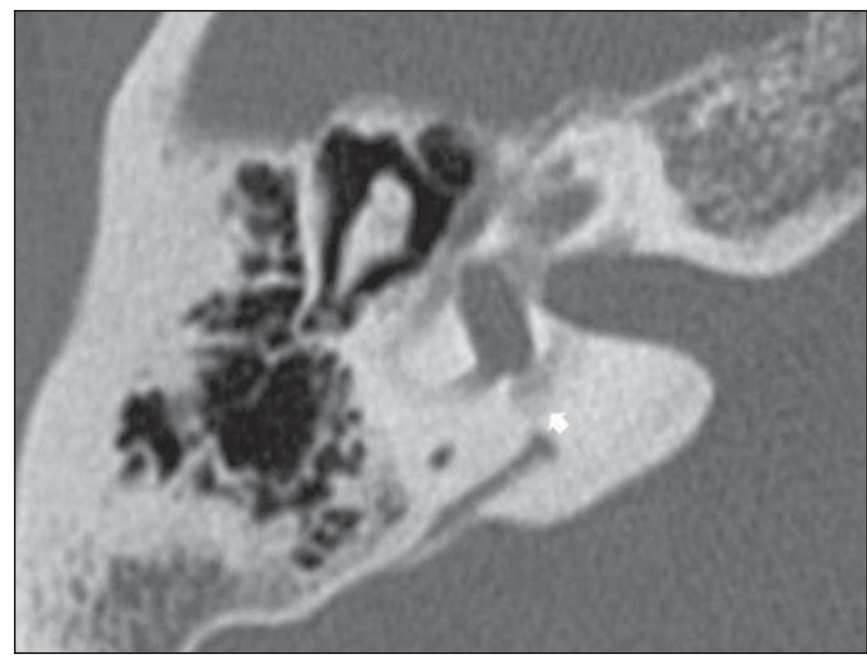

Figure 10. Axial CT section. Focus in the posterior labyrinth (arrow). 


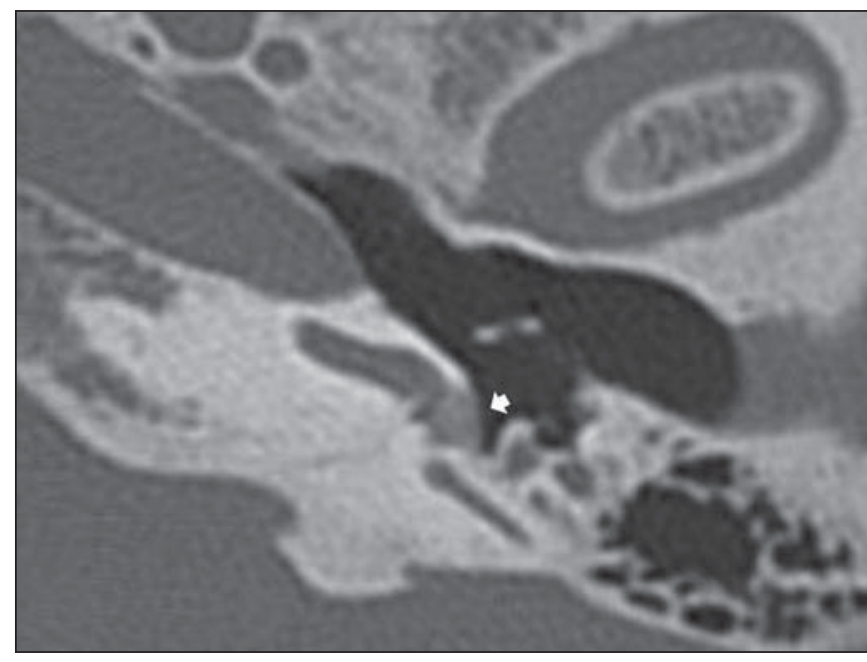

Figure 11. Axial CT section. Obliteration of round window (arrow).

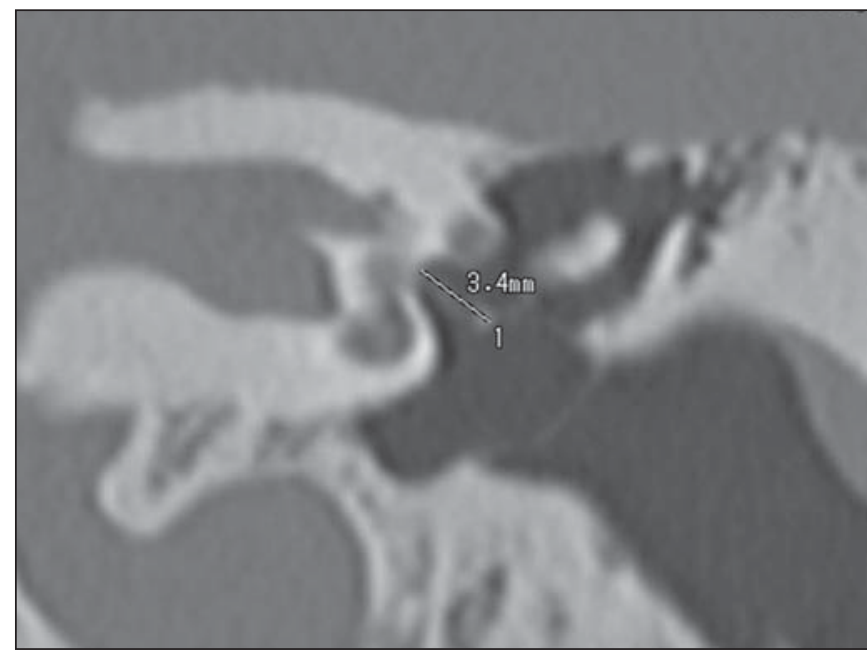

Figure 13. CT, coronal reconstruction. Distance from the incus to the stapes footplate.

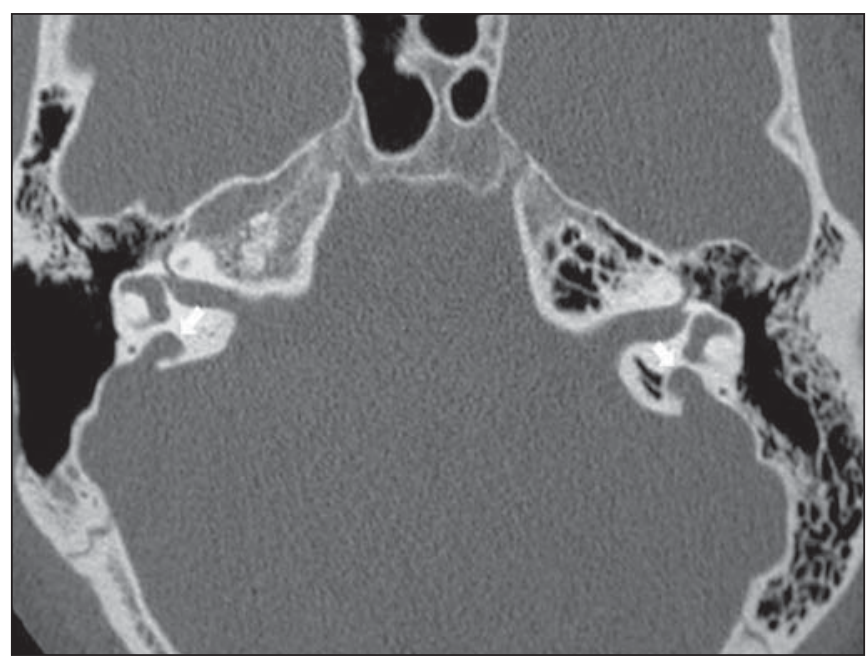

Figure 12. Axial CT section. Dilated vestibular aqueducts (arrows).

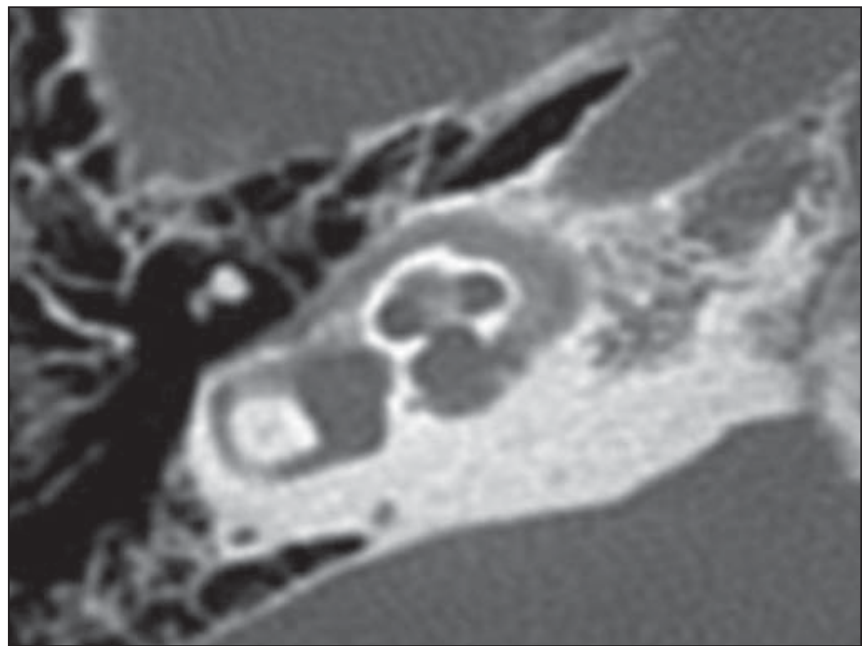

Figure 14. CT, axial, oblique reconstruction. Imperfect osteogenesis.
It is important to emphasize that the previously mentioned tomographic findings are not exclusive of otosclerosis, and that other diseases may generate similar alterations, such as otosyphilis, osteogenesis imperfecta (Figure 14) and Paget's disease ${ }^{(6)}$.

\section{CONCLUSION}

Multidetector computed tomography, with its different planes, has been increasingly utilized as it allows for the confirmation and appropriate characterization of otosclerosis, as well as the identification of other causes related to deafness, either mimicking or associated with such deafness, and preoperative anatomic evalua- tion. Even being useful in such a context, currently the main role of MRI is the investigation of active focus, intracanalicular extension of the focus and mainly the detection of postoperative complications. Thus the knowledge on the temporal bone anatomy and on the peculiarities of otosclerosis at MDCT is a skill expected of the general radiologist, since such knowledge is useful for an accurate diagnosis and appropriate management of such disease.

\section{REFERENCES}

1. Mori N, Toyama Y, Kimura N, et al. Detection of small fenestral otosclerotic lesions by high-resolution computed tomography using multiplanar reconstruction. Auris Nasus Larynx. 2013;40:3640.
2. Vicente AO, Penido NO, Yamashita HK, et al. Tomografia computadorizada no diagnóstico da otosclerose retrofenestral. Rev Bras Otorrinolaringol. 2004;70:74-82.

3. Miranda GG, Orellana PP, Matus CL, et al. Otosclerosis: análisis imagenológico con tomografia computada multicorte. Rev Hosp Clin Univ Chile. 2006;17:356-9.

4. Menif E, Bejjar S, Miladi S, et al. Diagnostic de l'otodpongiose et classification tomodensitométrique pronostique. Société Française de Radiologie. Posters électroniques. [acessado em $10 \mathrm{de}$ abril de 2012]. Disponível em: http://pe.sfrnet. org/ModuleConsultationPoster/consultation Poster.aspx ?intIdPoster $=4238$.

5. Poirrier V, Escude B, Granier I, et al. Imagerie de l'otospongiose. Société Française de Radiologie. Posters électroniques. [acessado em 10 de abril de 2012]. Disponível em: http://pe.sfrnet.org/ ModuleConsultationPoster/posterDetail.aspx? intIdPoster=1195.

6. Lee TC, Aviv RI, Chen JM, et al. CT grading of 
otosclerosis. AJNR Am J Neuroradiol. 2009:30: 1435-9.

7. Vicente AO, Penido NO, Yamashita HK, et al. Tomografia computadorizada no diagnóstico da otosclerose fenestral. Rev Bras Otorrinolaringol. 2004;70:66-73

8. Lagleyre S, Sorrentino T, Calmels MN, et al. Reliability of high-resolution CT scan in diagnosis of otosclerosis. Otol Neurotol. 2009;30:1152-9.

9. Rangheard AS, Marsot-Dupuch K, Mark AS, et al. Postoperative complications in otospongiosis: usefulness of MR imaging. AJNR Am J Neuroradiol. 2001;22:1171-8.
10. Craighero F, Van Driessche V, Van Dinther J, et al. Valeur de l'hypondensité préméatique interne (HDMI) dans l'otospongiose. In: Journées Françaises de Radiologie. 21-25 octobre; Paris, France. [acessado em 10 de abril de 2012]. Disponível em: http://pe.sfrnet.org/ModuleConsultationPoster/consultationPoster.aspx ?intIdPoster $=4897$.

11. Wycherly BJ, Berkowitz F, Noone AM, et al. Computed tomography and otosclerosis: a practical method to correlate the sites affected to hearing loss. Ann Otol Rhinol Laryngol. 2010;119:78994.

12. Ukkola-Pons E, Williams M, Ayache D, et al
Otospongiose préopératoire en quatrième vitesse: "ce que le chirurgien veut vraiment savoir". Société Française de Radiologie. Posters électroniques. [acessado em 10 de abril de 2012]. Disponível em: http://pe.sfrnet.org/ModuleConsultationPoster/consultationPoster.aspx?intIdPoster $=4233$.

13. Ou Y, Zhang Z, Chen S. et al. Cochlear otosclerosis: 3 cases report and literature review. Lin Chung Er Bi Yan Hou Tou Jing Wai Ke Za Zhi. $2009 \cdot 23: 14-6,20$ 